In the propanidid group six out of the 19 patients retched or vomited soon after regaining consciousness, whereas only one (in the halothane group) retched out of all the 46 patients in the other groups. The probability of this happening by chance is only 0.0019 (from Fisher's exact significance test).

\section{Discussion}

The persistence of the effects of intravenous anaesthetic agents in the postoperative period has been one of the principal objections to their use in outpatients, and the results of this study suggest that this reservation can be justified, especially in the case of thiopentone. Though recovery is quickly complete after purely inhalational anaesthesia with nitrous oxide, oxygen, and halothane, undoubtedly most patients, apart from small children, prefer an intravenous injection to the application of a mask for the induction of anaesthesia. Inevitably, therefore, many outpatients will receive intravenous anaesthesia and, furthermore, will very likely leave hospital before they are fully recovered. Fig. 4 shows that 30 minutes postoperatively extraocular imbalance was still present in $20 \%$ of patients after methohexitone, $30 \%$ after propanidid, and $70 \%$ after thiopentone. The imbalance at this time was of course only minor, but it is important that a test of postoperative recovery should be so sensitive that impairment which is otherwise not clinically obvious may be recognized. Work is in progress to develop an ocular test which may conveniently be used generally in clinics to assess recovery in outpatients who require anaesthesia or other medication for operations and diagnostic procedures.

The curves in Fig. 4 probably mainly reflect recovery due to physical redistribution of the anaesthetic agents. The recovery curves after propanidid and methohexitone are similar, and so it is interesting to speculate that recovery in both cases is largely due to redistribution, though propanidid is quite rap- idly metabolized to inactive products (Doenicke et al., 1968) whereas methohexitone is not (Brand et al., 1963). It is hoped to study these two agents for a longer period postoperatively, when metabolic degradation could be the principal factor governing complete recovery. Doenicke and Kugler (1965) reported electroencephalographic evidence of the activity of methohexitone up to 12 hours after its administration whereas there was no such prolonged effect after propanidid.

The high incidence of retching and vomiting in the early postoperative period after propanidid was a nuisance, but seemed to have remarkably little general effect on the patients; and recovery, as judged by the Maddox wing, was not significantly slower in those who vomited. Dundee (1965) also reported a high incidence of nausea and vomiting after propanidid, but this was not the experience of Zindler (1965).

I should like to thank Miss E. H. L. Duncan for her help and advice in the handling of the data.

REFERENCES

Brand, L., Mark, L. C. Snell, M. McM., Vrindten, P., and Dayton, P. G. (1963). Anesthesiology, 24, 331.

Clarke, R. S. J., Dundee, J. W., Barron, D. W., and McArdle, L. (1968). British foumal of Anaesthesia, 40, 593.

Doenicke, A., Krumey, I., Kugler, J., and Klempa, J. (1968) British fournal of Anaesthesia, 40, 415.

Doenicke, A., and Kugler, J. (1965). Acta Anaesthesiologica Scandinavica, Suppl. No. 17, p. 99. Dundee, J. W. (1965). Acta Anaesthesiologica Scandinavica, Suppl. No. 17,
p. 77.

Hannington-Kiff, J. G. (1970). Proceedings of the Royal Society of Medicine, 63, 73 .

Harrington, A. B., and Goodman, H. (1969). Health Trends, 1, No. 1, p. 2.

Zindler, M. (1965). Acta Anaesthesiologica Scandinavica, Suppl. No. 17, p. 75 .

\title{
Bacteriological Studies of the Modified Kiil Dialyser
}

\author{
D. M. JONES,* M.D., M.R.C.PATH., DIP. BACT. ; BARBARA M. TOBIN, $†$ PH.D., DIP. BACT. \\ G. R. HARLOW, $\ddagger$ M.B. ; A. J. RALSTON, $\$ M.B., M.R.C.P.
}

\begin{abstract}
Cummary: Bacterial proliferation in dialysis fluid during haemodialysis may be associated with rigors, hypotension, and bacteraemia. Investigations carried out in a period in which rigors were particularly common showed the source of bacteria to be parts of the gasket system of the Kiil dialyser, areas that are inaccessible to disinfectants.
\end{abstract}

\section{Introduction}

Intermittent haemodialysis is now widely used in managing terminal chronic renal failure. Early in the development of the technique, particularly when recirculating systems were used, bacterial proliferation in the dialysis fluid was found to be common and sometimes associated with rigors, shock, and

\footnotetext{
* Consultant Bacteriologist.

tResearch Assistant.

†linical Assistant.

Consultant Physician

Withington Hospital, Manchester 20
}

even bacteraemia (Sherris, Cole, and Scribner, 1961; Curtis, Wing, and Coleman, 1967).

During June, July, and August 1969 an increasing number of severe reactions, consisting of rigors, high fever, and hypotension, occurred among the patients in the Withington Haemodialysis Unit. Nearly all these reactions began about one hour after beginning dialysis, and some were accompanied by bacteraemia due to Enterobacter aerogenes, this same organism being isolated from the blood stream of several patients. These findings led us to conduct a bacteriological study of the Kiil dialyser at various stages of building and, in particular, to examine the bacteriological state of the prepared dialyser just before dialysis.

\section{Method}

We use modified Kiil dialysers (Cole, Quinton, Williams, Murray, and Sherris, 1962), referred to as types A and B, obtained from two of the English manufacturers, the patients receiving three 10-hour dialyses a week. The modified Kiil 
dialyser consists of three polypropylene boards which are held in a metal clamping frame. The opposing faces of the boards are machined into fine grooves, and two layers of the cuprophane 150 PT membrane are placed between the boards, the blood flowing between the layers of cuprophane, the dialysis fluid flowing in the contralateral direction between the cuprophane and the polypropylene board. At the periphery of the boards a seal is maintained by a rubber gasket attached to the board by adhesive. The design of the gasket varies according to the manufacturer. The ports which allow access of blood to the dialyser are held in position by an additional gasket on each board.

The preparation of the dialyser involves building the previous day, the boards having been soaked before this for at least one hour in hypochlorite solution. This is followed by overnight disinfection of the assembled dialyser with $2 \%$ formaldehyde, washing through the dialysis compartments with tap-water for one hour, and finally priming the blood compartment with sterile saline. The preparation of the dialyser is normally complete about two hours before use.

Some dialyses on the unit are routinely monitored by sampling dialysate entering and leaving the dialyser towards the end of dialysis. The bacterial counts on these samples are performed by the dip-slide method (Guttman and Naylor, 1967). In the present investigation, in addition to performing more precise counts at the start and also later in dialysis, the prepared dialysers were examined before dialysis. Just before the dialyser was connected to the dialysate supply, bacterial counts were made on the residual fluid obtained from the dialysate compartment by tipping the dialyser. Dialysers were graded "clean" if these counts .were less than 100 organisms/ ml. or "dirty" if the count exceeded this number. When the patient was connected to the dialyser the saline displaced from the venous end of the blood compartment was collected and the bacteria in this were counted. Observations were made on the subsequent clinical progress during dialysis, and blood cultures were taken from patients who developed reactions and also from some patients who did not. All the bacterial counts were performed by the pour plate method and the plates incubated at $37^{\circ} \mathrm{C}$. overnight.

\section{Results}

The dialysate entering the dialyser from the proportionating machines was bacteriologically satisfactory. From analysis of the results (Table I) we realized that some of the individual dialysers were regularly contaminated and that these belonged to the patients who frequently had reactions. We were surprised to discover Enterobacter aerogenes within the blood compartments despite prolonged exposure to adequate concentrations of formaldehyde. Other dialysers regularly remained "clean" and gave the associated patients no trouble. The fault obviously lay in the individual dialysers rather than the dialysate supply. We also observed that type $B$ dialysers were more often contaminated than type $A$.

As a consequence of these findings several dialysers were removed from service. After this we observed that reactions in the patients were now rare and the dialyses performed over another period were observed with techniques identical to those used previously. The bacteriological situation was now very different (Fig. 1 and Table II). Since this time, whenever we have detected large numbers of bacteria in the dialysis fluid effluent originating in the dialyser itself we have withdrawn that dialyser and fitted it with new gaskets.
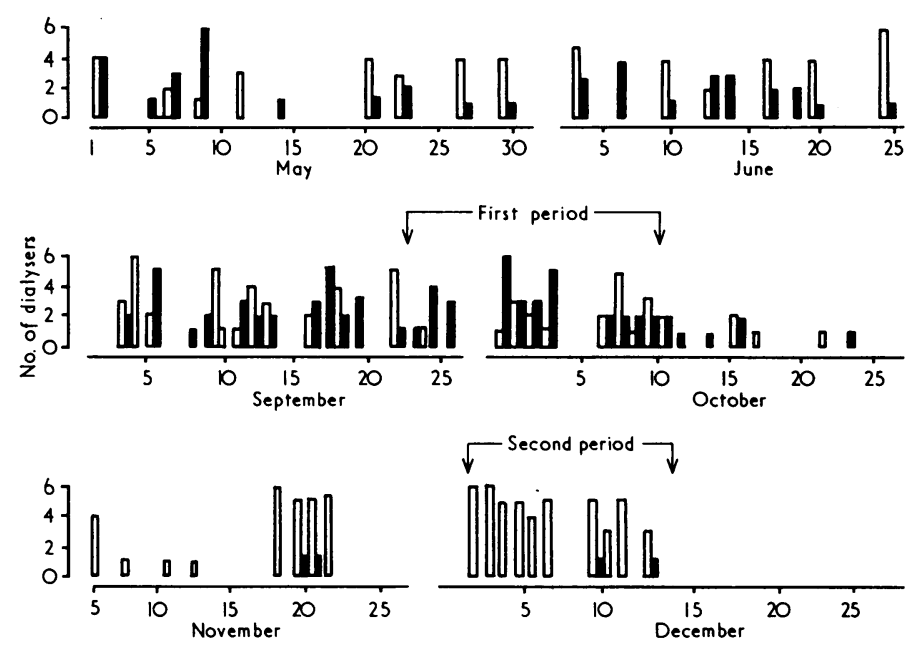

FIG. 1.-Routine monitoring of dialyser effluent. Dialyser effluent with more than $10^{5}$ organisms $/ \mathrm{ml}$. $\square$ Dialyser effluent with less than $10^{5}$ organisms $/ \mathrm{ml}$.

\section{Examination of Defective Dialysers}

Some of the five dialysers withdrawn from use were dismantled and the boards left to dry for several days. The gaskets were then removed and the gasket grooves and housings in the boards examined macroscopically for residual moisture and cultured for the presence of bacteria. In these dialysers there were still moist areas beneath the gaskets. Beneath the long gasket the side with the end-to-end joint was more often moist; the lumen of the hollow gasket near this joint was also sometimes wet. Residual moisture was observed beneath the blood port gaskets (types A and B) and in the lumen of the small rubber insert (type B). The application of pressure to the blood port gaskets before removal often

TABLE I.-First Period. Observations on 56 Dialyses During 11 Consecutive Days. Fourteen Patients were Dialysed; 13 Reactions Occurred in Six Patients -Blood Compartments from Two Dialysers $(*)$, and Blood Compartments from Four Dialysers $(\dagger)$

\begin{tabular}{|c|c|c|c|c|c|c|c|c|c|c|c|c|c|c|c|}
\hline \multirow{2}{*}{\multicolumn{6}{|c|}{ No. and Type of Dialyser }} & \multicolumn{3}{|c|}{ Dialysate Compartments } & \multicolumn{3}{|c|}{ Blood Compartments } & \multicolumn{2}{|c|}{ Clinical Reactions } & \multicolumn{2}{|c|}{ Blood Cultures } \\
\hline & & & & & & Examined & Clean & Dirty & $\overline{\text { Examined }}$ & Sterile & Contaminated & Absent & Present & Negative & Positive \\
\hline $\begin{array}{l}\text { Type A-7 } \\
\text { Type B-7 }\end{array}$ & . & $\begin{array}{l}\ldots \\
\cdots\end{array}$ & 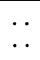 & $\ldots$ & 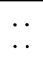 & $\begin{array}{l}25 \\
31\end{array}$ & $\begin{array}{r}20(80 \%) \\
7(23 \%)\end{array}$ & $\begin{array}{r}5(20 \%) \\
24(77 \%)\end{array}$ & $\begin{array}{l}19 \\
31\end{array}$ & $\begin{array}{l}15(79 \%) \\
16(51 \%)\end{array}$ & $\begin{array}{r}* 4(21 \%) \\
+15(49 \%)\end{array}$ & $\begin{array}{l}24 \\
19\end{array}$ & $\begin{array}{r}1(4 \%) \\
12(39 \%)\end{array}$ & $\begin{array}{l}3 \\
5\end{array}$ & $\begin{array}{l}\mathbf{0} \\
3\end{array}$ \\
\hline
\end{tabular}

TABLE II.-Second Period. Observations on 49 Dialyses During 10 Consecutive Days. Thirteen Patients were Dialysed; no Reactions were Observed

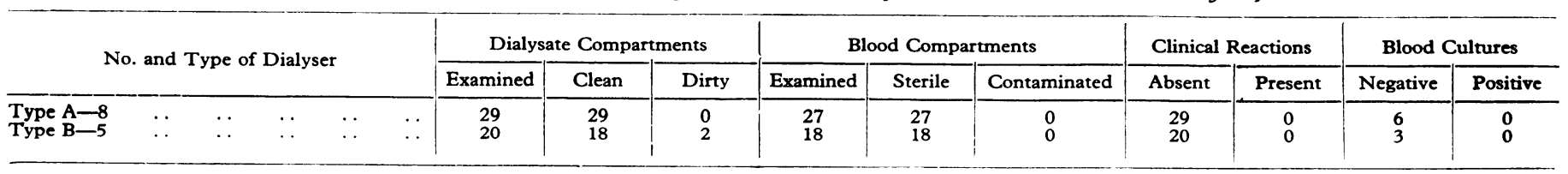


produced a small bead of moisture (Fig. 2). Wherever moisture was seen a profuse mixed growth of Gram-negative organisms was obtained with $E$. aerogenes predominating.

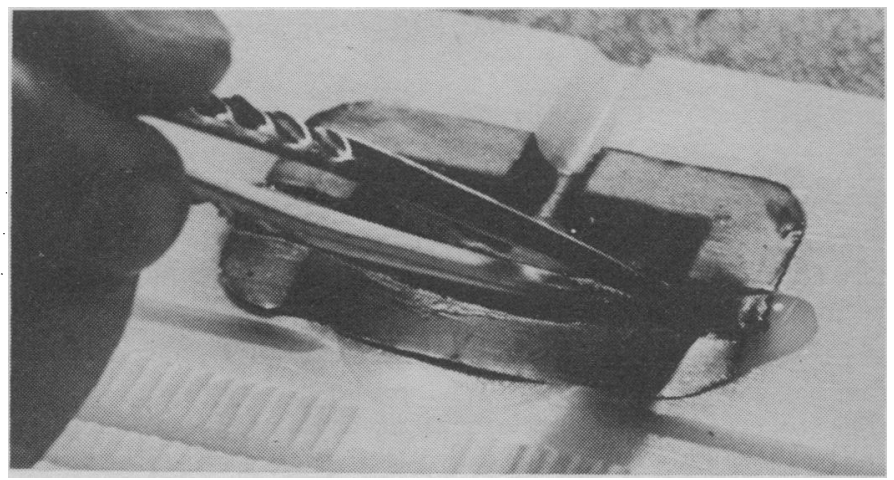

Fig. 2.-Fluid expressed from beneath blood port gasket: the board had been left to dry for five days.

Subsequently we examined the gasket housings of both types of dialyser that did not have a history of regularly infecting the dialysis fluid. Invariably many bacteria were found (Fig. 3), though there were qualitative differences in the bacterial flora. Since the episode of reactions described, $E$. aerogenes has not often been present and the flora has been predominantly non-pigmented Pseudomonas sp., Achromobacter sp., and to a lesser extent Ps. aeruginosa.

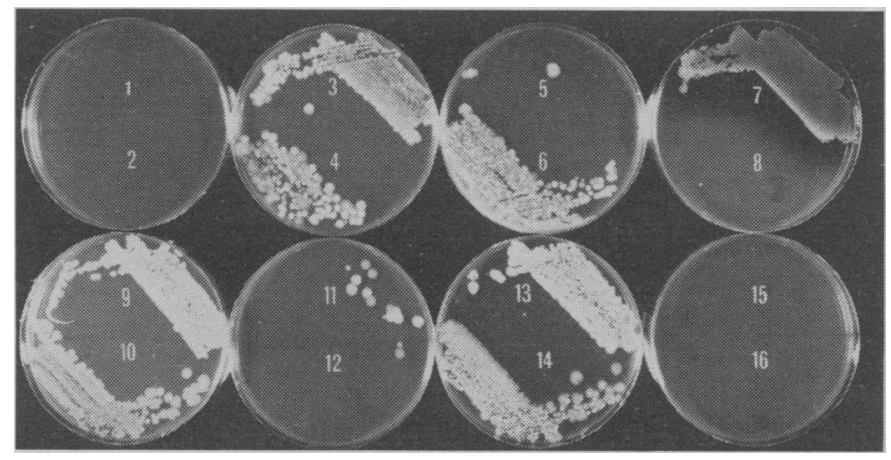

FIG. 3.-Bacterial flora beneath the gaskets of a Kiil dialyser prepared for use. Top Board.- (1) Dialysate outlet. (2) Transfer port. (3) and (4) Groove, side of end-to-end gasket joint. (5) Groove, opposite side. (6) Under blood port gasket (arterial). (7) Under blood port gasket (venous) Middle Board.-Upper surface: (8) Under blood port gasket (arterial). (9) Under blood port gasket (venous). Lower surface: (10) Groove, side of end-to-end joint. (11) Groove, opposite side. (12) Under blood port gasket (venous). (13) Under blood port gasket (arterial). Lower Board.(14) Under blood port gasket (arterial). (15) Under blood port gasket (venous). (16) Dialysate inlet.

\section{Discussion}

It has been our experience, like that of others (Kidd, 1964), that bacterial counts over $10^{5} / \mathrm{ml}$. in the dialysis fluid may be associated with pyrogenic reactions in the patients. The extent of bacterial contamination and growth in the dialysate circuit depends on many factors. These are described, and the need for regular bacteriological monitoring of the equipment is emphasized, in the Working Party Report to the P.H.L.S. (Report, 1968). In our haemodialysis unit some of the Kiil dialysers were heavily infected with $E$. aerogenes and other Gram-negative organisms. This led to bacterial proliferation in the dialysate and on the dialyser membranes, with very high bacterial counts in the dialysis effluent, and, in turn, to a high incidence of reactions in some of the patients. The most severe reactions were found to be associated with bacteraemia due to $E$. aerogenes. The source of the bacteria was the spaces beneath the gaskets on the dialyser boards. From these sites the bacteria not only contaminated the dialysate compartments but were also sometimes found in the blood compartment of prepared dialysers before use. In these dialysers a thick suspension of organisms could be expressed from beneath the blood port gaskets. Under the conditions of compression at this point bacteria may penetrate cuprophane membrane. We could not account for the presence of $E$. aerogenes in the blood compartments in any other way. When the dialysers associated with regularly contaminated dialysate compartments were withdrawn the incidence of reactions in the patients was much reduced.

We think that there is a design fault in the Kiil dialyser in so far as disinfectant is unlikely to gain access to small voids that inevitably occur beneath the gaskets. These areas regularly harbour many bacteria. In particular the gasket grooves of the type B dialyser are rough, creating many small voids between the gasket and the board. The small piece of hollow gasket inserted into the blood port gasket of this type of dialyser is also very apt to harbour organisms. When a hollow tubular gasket is used moisture and bacteria may gain access to the lumen unless great care is exercised at end-toend jointing. In the type $A$ dialyser the gasket groove is generally more satisfactory, but bacteria may collect beneath the corners of the blood port gasket.

A readily removable gasket system, not requiring adhesive and allowing free access of disinfectant to the gasket housing, would seem to us to be a more satisfactory design.

We wish to thank the nursing staff of the intermittent haemodialysis unit for help with the collection of specimens and Mr. Peter Davis for technical assistance. This work was supported by a grant from the Research Subcommittee of Manchester Regional Hospital Board.

\section{REFERENCES}

Cole, J. J., Quinton, W. E., Williams, C., Curray, J. S, and Sherris, J. C. (1962). Transactions. American Society for Artificial Internal Organs, 8, 209.

Curtis, J. R., Wing, A. J., and Coleman, J. C. (1967). Lancet, 1, 136. Guttman, D., and Naylor, G. R. E. (1967). British Medical fournal, 3, 343.

Kidd, E. E. (1964). British Medical fourmal, 1, 880

Report to the Public Health Laboratory Service by the Working Party on Haemodiolysis Units (1968). British Medical fournal, 3, 454.

Sherris, J. C., Cole, J. J., and Scribner, B. H. (1961). Transactions. American Society for Artificial Intermal Organs, 7, 37. 